\title{
Repensando as relações raciais no Brasil: o estatuto da igualdade racial $e$ as suas implicações na luta antirracista
}

\author{
Joyce Amâncio de Aquino Alves ${ }^{\mathrm{a}}$
}

Oliveira, Sidney de Paula. O Estatuto da Igualdade Racial. São Paulo: Selo Negro, 2013.

A obra de Sidney de Paula Oliveira trata de um tema bastante relevante, qual seja, o Estatuto da Igualdade Racial e suas implicações na sociedade brasileira. Ao tratar dessa temática, o autor apresenta a peculiaridade do racismo brasileiro, comumente representado como um racismo cordial. Um dos responsáveis pela imagem de paraíso racial e cordialidade entre as raças é Gilberto Freyre, cuja obra Casa Grande \& Senzala é apontada por muitos estudiosos como uma das referências do Mito da Democracia Racial, falácia que permeia as análises das relações raciais no Brasil em seu processo de formação.

O autor do livro é especialista em Direito, com vasta experiência nas áreas de Direitos Humanos, Cidadania e Relações Raciais. Em O Estatuto da Igualdade Racial, dedica-se a um conteúdo de legislação composto pelas principais leis sobre as relações raciais no Brasil até a criação da Constituição em 1988, incluindo também aí o Estatuto da Igualdade Racial. De forma bastante didática e acessível, valendo-se de um vocabulário e de uma linguagem que permitem uma boa compreensão do debate, o livro, que corresponde ao sétimo volume da "Coleção Consciência em Debate”, da Selo Negro Edições, trata da temática racial no Brasil em suas dimensões teóricas e práticas, tendo em vista que as raízes do Mito da Democracia Racial dificultam o exame da situação desigual que envolve as condições de vida entre brancos e negros, deixando de lado o fenômeno do racismo.

O livro abrange o perído inaugurado pelo reconhecimento, pela unanimidade do Supremo Tribunal Federal (STF), da constitucionalidade das ações afirmativas, enfatizando principalmente as cotas para negros na Educação. Sidney de Paula Oliveira destaca a importância de acompanharmos a história da questão racial no Brasil, analisando como foram tomadas algumas ações políticas relativas à questão do racismo, e que se desdobraram em leis específicas para o tratamento dessa questão. O livro se propõe a realizar, de uma forma geral, alguns apontamentos

a Graduada em Relações Internacionais pela Universidade Estadual da Paraíba (UEPB). Mestra em Ciências Sociais pela Universidade Federal de Campina Grande (UFCG) e doutoranda em Sociologia pela Universidade Federal de Pernambuco (UFPE). Membro do Núcleo de Pesquisa de Relações Raciais Frantz Fanon (NUPERR/UFPE). 
críticos acerca do Estatuto da Igualdade Racial (lei n. 12.288/2010) e, além disso, das discrepâncias entre o projeto de lei original e o texto legal aprovado durante o governo Lula.

Para tanto, o autor parte da análise do projeto de lei n. 213/2003, proposto pelo senador Paulo Paim (PT-RS) e que, em sua visão, estava não só calcado em ideais humanitários como também atendia muitas das demandas dos movimentos sociais negros. Isto posto, o autor lança o seguinte questionamento: a sanção da lei representou concretamente uma conquista ou apenas esvaziou uma perspectiva simbólica? O objetivo da discussão desenvolvida no livro é o de compreender as implicações principais da lei, no intuito de estimular a reflexão sobre as relações raciais.

O autor organiza o conteúdo da obra em sete capítulos, detalhando com precisão como os políticos envolvidos participaram dos processos de elaboração, discussão e sanção da lei. No primeiro capítulo, trata da expectativa dos movimentos sociais negros em torno da questão e aborda de forma breve a legislação que engloba as relações raciais no país. Aponta cronologicamente as principais leis antirracistas promulgadas a partir da independência do Brasil em $1822 \mathrm{e}$, em seguida, as leis Euzébio de Queiroz, Lei do Ventre Livre, Lei dos Sexagenários e a decisiva Lei Áurea, que encerraria o processo de escravidão, ao menos formalmente. Neste capítulo, destaca também o contexto da Proclamação da República, da promulgação do Código Penal e da Lei Afonso Arinos de 1988, assinalando como, a partir da Constituição Federal, os movimentos sociais negros passaram a se articular visando à proposição e aprovação de leis que atendessem suas expectativas, em um contexto pós-ditadura marcado pela ampliação dos espaços de exercício da cidadania (e das pressões daí decorrentes) e de gozo de direitos.

Em seguida, no capítulo dois, o autor enfoca alguns dispositivos introdutórios da Constituição Federal sob o ponto de vista formal, tendo em vista que até então o racismo era considerado uma mera contravenção penal sem consequências legais para quem o praticasse. O racismo se tornou um crime inafiançáfel e imprescritível apenas com a promulgação da Constituição, o que trouxe grandes mudanças para a sociedade brasileira e para o trato das relações raciais.

Ao longo do terceiro capítulo o autor analisa as diferenças existentes entre o projeto de lei e a lei sancionada. Trata-se de um capítulo bastante bem elaborado, no qual argumenta-se que o ideal presente no projeto ficou distante da realidade sancionada em lei, como sinalizam as mudanças nos termos empregados e nas medidas propostas, as quais redundaram em um texto que parecia não reconhecer a condição de profunda desigualdade a ser vencida. Segundo a análise, um dos 
dispositivos mais emblemáticos, e que não foi considerado no texto do projeto da lei, se refere a eventuais reparações e compensações, pois o projeto previa tanto medidas reparatórias quanto compensatórias, que incluíssem políticas públicas pontuais e direcionadas aos negros. Todavia, no texto da lei, os termos "reparação" e "compensação" não foram contemplados, restando apenas o termo "inclusão".

Merece comentário também o fato de que o texto do projeto de lei indicava a "valorização da diversidade racial", enquanto o texto da lei contemplou a frase "valorização da igualdade étnica e o fortalecimento da identidade nacional brasileira”. A lei desprezou a expressão "valorização da diversidade racial”, que não deixa de ser genérica, preferindo “igualdade étnica". Mas, quando propõe o fortalecimento da identidade nacional brasileira, corrobora a existência da tão falaciosa democracia racial (OliveIRA, 2013, p. 53).

Sobre a identidade nacional brasileira, abandonar a frase referente à "diversidade racial" tinha como objetivo consolidar a noção de identidade, não contemplando a questão racial, uma vez que o discurso da identidade nacional coaduna-se com a falácia da Democracia Racial, da unidade das três raças (negra, branca e indígena), tão significativa para a explicação da identidade e do racismo no Brasil, como bem examinado por Roberto Da Matta. Em outras palavras, a ideia de igualdade étnica não problematiza de forma direta a questão racial, e a sua adoção, segundo o autor do livro, acabou por “desracializar” o texto final do projeto.

No quarto capítulo, o autor realça alguns pontos relevantes do projeto de lei, enfatizando que tanto o texto do projeto quanto o da lei sancionada não trazem dispositivos e princípios de força coercitiva e vinculativa, mas apenas diretrizes genéricas e que também são comuns em textos legais que falam em "promover, incentivar, estimular, contribuir", etc, mas que não são tão eficazes para a implementação de políticas públicas.

Nos capítulos cinco, seis e sete, o autor aponta algumas saídas para os impasses colocados pela lei, analisa o papel desempenhado pelo relator do projeto de lei e, por último, apresenta alguns dos segmentos sociais favoráveis e contrários ao projeto de lei sancionada. Por fim, propõe ressaltar, inclusive como uma oportunidade histórica para a militância antirracista, a questão das ações afirmativas, em especial a modalidade das políticas de cotas para a promoção da igualdade. Sidney de Paula ressalta que, embora tenha sido alterado em seus pontos mais relevantes, o projeto de lei do Estatuto da Igualdade Racial era o máximo que se poderia obter naquele momento: 
Para o autor, havia a intenção de "desracializar" o texto final, com a notória substituição do termo "raça" pelo termo "etnia". Outro ponto refere-se ao fato de que, embora o projeto mencionasse "imediatas iniciativas", o texto da lei sancionada ignorou a urgência das decisões a serem tomadas. O autor oferece várias ilustrações de como a problemática racial brasileira foi mascarada e mitigada, como por exemplo com a substituição da expressão "desigualdades raciais" por "desigualdades sociais".

É necessário atentar para o fato de que não apenas alguns termos foram alterados, mas também que o quesito cor/raça foi retirado do projeto nas análises de saúde e educação. Na saúde, se houvesse a coleta de dados quanto à cor e à raça, seria possível desenvolver políticas públicas voltadas para esse segmento da população, principalmente quando se trata de patologias que acometem esse segmento com maior incidência. Basta ver que o proponente do projeto de lei se preocupou com os casos de doenças que prevalecem na população afro-brasileira, como a anemia falciforme. Na educação, o quesito cor/raça constava no projeto como "diferenças raciais" e foi sancionado como "diferenças étnicas".

Em outros termos, a obra investiga os pressupostos da Democracia Racial presentes na lei, cujo principal indício é uma linguagem "amenizada", e que implicou na redução do impacto que o Estatuto da Igualdade Racial poderia ter produzido. São realçados cinco pontos nucleares no livro, que seguem abaixo (não necessariamente em hierarquia de importância):

1. Percentual mínimo para negros nas universidades, na televisão e nos partidos políticos;

2. Programas que assegurem vagas para negros em instituições federais de nível médio e superior;

3. Incentivos fiscais às empresas que contratarem negros;

4. Definição dos quilombos remanescentes;

5. Exigência de que o Sistema Único de Saúde (SUS) identifique pacientes pela raça.

Acompanhando as análises empreendidas pelo autor, que apontam para a substituição dos termos e a generalização de algumas definições importantes, percebe-se como houve uma negociação da linguagem e das ações a serem pensadas sobre a temática racial, para que se avançasse no combate à discriminação. $\operatorname{Em} O$ Estatuto da Igualdade Racial, fica evidente como ainda é difícil legitimar a luta antirracista e as necessidades de um segmento da população que é alvo de um 
racismo não declarado e pouco debatido. Todavia, analisando de forma qualificada o processo político envolvido e o contexto político e social no qual se deu a criação do Estatuto, o autor identifica as dificuldades que se impõem à concretização das ações afirmativas, com discussões como a de miscigenação da população e de paraíso racial.

O argumento central do livro consiste em mostrar como os esforços contidos no projeto original de lei foram descaracterizados e minimizados pela forma como a lei foi sancionada. Tendo isso em vista, o autor está interessado em destacar a necessidade de se repensar as relações raciais no Brasil, sobretudo quando se compreende a dinâmica dos segmentos sociais contra e a favor do Estatuto - dos quais participam intelectuais, políticos e militantes -, concluindo assim que não houve a conquista tão esperada.

Não obstante, as considerações do autor acerca das discrepâncias entre o projeto de lei e a lei sancionada são categóricas e precisam ser refletidas e problematizadas para melhor compreendermos as relações raciais no Brasil. A compreensão que prevalece entre aqueles que sancionaram a lei é a de que vivemos ainda nos moldes da Democracia Racial e de que, portanto, deve-se encampar o projeto político de não nos projetarmos como um país racista. Porém, as estratégias de luta travadas pelos militantes dos movimentos negros estão direcionadas diretamente para essa ambiguidade, na medida em que buscam uma conscientização sobre racismo e discriminação e uma reivindicação pela igualdade, explorando novas interpretações acerca da instauração da Democracia Racial.

[...] o fato é que o movimento negro fez da denúncia do mito da democracia racial seu mote mobilizador central durante todo o período das décadas de 1970 a 90. Essa centralidade renderá frutos e reações, seja por meio de políticas públicas e legislação, seja por meio de novas teorias acadêmicas sobre a "democracia racial". (Guimarães, 2001, p. 159).

O mito da Democracia Racial, portanto, ainda faz parte do trabalho de desconstrução dos militantes antirracistas e dos estudiosos das relações raciais, lado a lado com novas teorias acadêmicas críticas do pensamento social e político que pretende retratar o Brasil como o país do sucesso da miscigenação e da confraternização entre as raças. O autor revela como simplesmente "apontar caminhos" está muito aquém do propósito de superação das desigualdades raciais.

A leitura do livro permite observar a existência de alguns entraves políticos e jurídicos colocados durante a formulação e a implementação do Estatuto da 
Igualdade Racial, que enquanto projeto tinha um grande potencial, mas que foi modificado e descaracterizado em sua versão final. Porém, tais alterações não passaram despercebidas, sobretudo entre aqueles setores da sociedade que, como os movimentos sociais negros, lutam, com a sua militância, para "descortinar" o racismo e alcançar as transformações necessárias para a concretização da igualdade racial na sociedade brasileira.

\section{REFERÊNCIAS BIBLIOGRÁFICAS}

DA MatTA, Roberto. "Digressão: a fábula das três raças, ou o problema do racismo à brasileira”. In: Roberto Da Matta. Relativizando: uma introdução à antropologia social. Petrópolis: Vozes, 1983.

Freyre, Gilberto. Casa Grande \& Senzala. 41 ${ }^{\text {a }}$ edição, Rio de Janeiro, Record, 2000.

Guimarães, Antônio S. "Nacionalidade e Novas Identidades Raciais no Brasil: Uma

Hipótese de Trabalho”. In: Jessé Souza (Org.) Democracia Hoje. Brasília: Editora UnB, 2001.

Oliveira, Sidney de Paula. O Estatuto da Igualdade Racial. São Paulo: Selo Negro, 2013. 